\title{
Alternative funding plans: Academic GI groups beware!
}

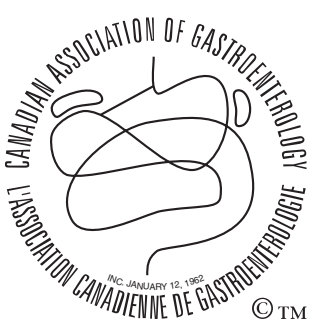

En français voir page 515

\author{
Desmond Leddin MB FRCPC \\ Professor and Head, Division of Gastroenterology, Dalhousie University, and
}

Service Chief, Gastroenterology, Capital District Health Authority

$\mathrm{T}$ he purpose of this news page is to present some aspects of the experience with an alternative funding plan (AFP) at Dalhousie University, Halifax, Nova Scotia. While primarily of interest to university gastroenterology (GI) groups, there are lessons for anyone who interacts with government.

AFPs as a mechanism of physician remuneration have grown in popularity over the past decade. These plans provide an alternative to traditional fee-for-service (FFS) billing. Some provide remuneration for clincal services only, while others, such as the one at Dalhousie University, are designed to provide remuneration for administrative, educational and research activities in addition to clinical work.

The advantage of AFPs from a government perspective is that the finance department can more accurately project and budget health care expenditures. The government also has an interest in ensuring that sufficient numbers of medical personnel, both specialists and family practitioners, are available to meet the needs of the population. An AFP allows comprehensive medical services to be put in place.

The advantage for GI groups is that while many of the services we provide are catered for by traditional billing, many are not. Liver transplantation, hepatitis programs, complex inflammatory bowel disease consults and inpatient care are examples of activities that do not lend themselves well to FFS.

From a patient perspective, some patient groups (those whose needs are not easily met by FFS) benefit. It is possible to spend more time with patients, develop collaborative practices with nursing and other health care providers, and provide specialist clinics.

At the moment, AFPs are in place for the GI groups at The Hospital for Sick Children, Toronto, Ontario; Dalhousie University; Queen's University, Kingston, Ontario; and the University of Calgary, Calgary and the University of Alberta, Edmonton, Alberta. In Halifax and Kingston, virtually all of the gastroenterologists are on AFPs because there is a paucity of community-based GI groups.

The recent experience in Halifax where the Department of Medicine came within a handful of votes of dissolution should give other academic groups reason to pause before moving to an AFP model. The reasons for this are worth recounting and illustrate some of the problems posed by the AFP system.
There is another process afoot that increases the hazard of academic groups joining AFPs. Canadian university hospitals have not been immune to the health system management drive to merge hospitals into large health districts. The rationale for this is primarily financial, in the hope that economies will result from the development of integrated districts. The result from an academic perspective, however, is that academic groups have been merged with hospitals and physician groups whose primary function is clinical work, often clinical work with a primary care focus. In many centres, the academic group, because that is often where the headship of the Department of Medicine resides, has become responsible for the clinical care of the health district.

The Department of Medicine at Dalhousie University negotiated its first AFP model in December 1998. It was designed to improve the retention and recruitment of physicians, make the Department of Medicine financially competitive with the national marketplace and to encourage innovative ways of delivering care.

Recruitment and retention issues were largely solved and the Department of Medicine grew. The health district and the university were happy with the deal because their administrative and teaching needs could be met under the AFP. The attitude of the medical society was perceived to be ambivalent. Because there is a finite amount of money available in any province for physician remuneration, giving a larger slice to one group inevitably leads to infighting. Patient satisfaction varied. Complaints about waiting times to see specialists began to be tabled with the Department of Health from primary care physicians and patients. There was widespread recognition that sick patients were seen promptly but the majority of referrals to high-volume specialties such as GI and cardiology were not acutely ill, and wait times spiralled. Whether this was a result of the Department of Medicine physicians no longer being driven by FFS or because of problems with the health district as a whole became a matter of heated debate.

The stage was then set for subsequent negotiations between the parties. An expanding Department of Medicine, which had moved further away from being viable under FFS, was now responsible for delivering health care to the health district. An

The CAG is proud to acknowledge its Benefactor Corporate Sponsors:

$\begin{array}{ccc}\begin{array}{c}\text { Abbott Laboratories Ltd } \\ \text { Janssen-Ortho Inc }\end{array} & \text { AstraZeneca Canada Inc } & \text { Axcan Pharma Inc } \\ \text { Pfizer Canada Inc } & \text { Schering Canada Inc }\end{array}$


ambivalent medical society, which was both negotiating with, and for, the Department of Medicine and the Department of Health, which could see both costs and complaints (at least from some primary care doctors) rising in unison. The University perceived the deal positively and remained supportive, as did the health district.

The most recent AFP expired in spring 2004. The government requested an extension of the deal to conduct an audit of the AFP from a value-for-money perspective.

The main conclusion was that the Department of Health could not be assured that the AFP was delivering value for money. Because one of the objectives of the AFP was to deliver alternative methods of health care (such as telephone consultation), but no mechanism had been developed to assign a value to this activity, this result was predictable. A number of recommendations were made. Many of these were reasonable and justifiable. Some, however, were designed to ensure that the Department of Health did, in the future, receive value for the taxpayer's funds. Inevitably, increased government control was recommended. Because the AFP included academic as well as clinical deliverables, the recommendations would move the Department of Medicine group closer to direct government control.

In a move that took even those of us used to the ways of government by surprise, the Department of Health then appointed their auditor as their negotiator for the renewed agreement! The result was predictable. The Department of Health proposed an agreement that was strong on control and poor on benefits. The Department of Health refused to discuss the national marketplace and generally behaved as if the Department of Medicine physicians were employees of the health district. One of my personal favourite sections of the agreement was the one that mandated that GIs would meet provincial standards for wait times, with no reference to the resources available to meet the targets. The Department of Medicine physicians voted narrowly to accept this agreement because they thought they had no other viable alternative.

A number of lessons can be learned from this sorry tale. The life cycle of the AFP can be summarized as follows:

1. An academic department has a need for an alternative to FFS.
2. The department negotiates an AFP.

3. The AFP results in increased specialization and growth of the department, which moves away from being viable under FFS.

4. Family doctors complain of reduced access to specialists.

5. The government triggers an audit before spending more money.

6. The audit concludes that it cannot be sure that government is getting value for money.

7. The government presents an unpalatable settlement to the physician group, which is not viable under FFS, and tries to reduce physicians to civil servant status.

8. Return to square one, except now what is needed is an alternative to the AFP.

The main lessons learned are:

1. Academic departments should approach health district mergers with a great deal of caution. There is a real possibility of the Department of Medicine becoming responsible for the clinical work of the district. This is not necessarily a bad thing, unless the resources do not come with the responsibility.

2. It is unwise to put all the eggs into the AFP basket. Always retain the possibility of returning to FFS.

3. If an AFP is accepted, ensure that primary care needs are met.

4. AFPs are an invitation to increased direct government control. Because the government is primarily concerned with clinical deliverables, the Department of Medicine may become preoccupied with the clinical agenda.

\section{SUMMARY}

AFPs have their benefits, but can have significant undesirable effects as well. In my opinion, they do have a role in the delivery of GI care, but only if the possibility of returning to FFS remains an option and only if sufficient numbers of gastroenterologists remain community-based to ensure that primary care needs are met. 


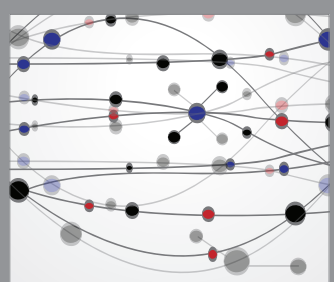

The Scientific World Journal
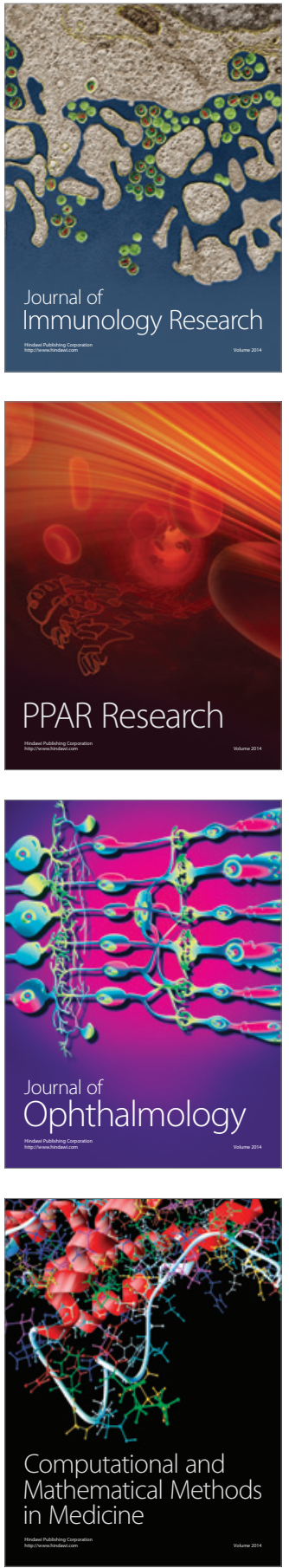

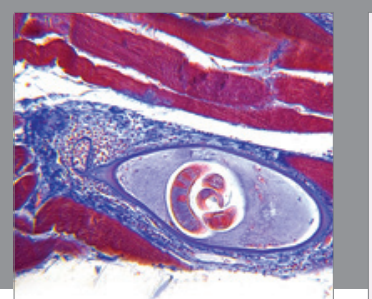

Gastroenterology Research and Practice

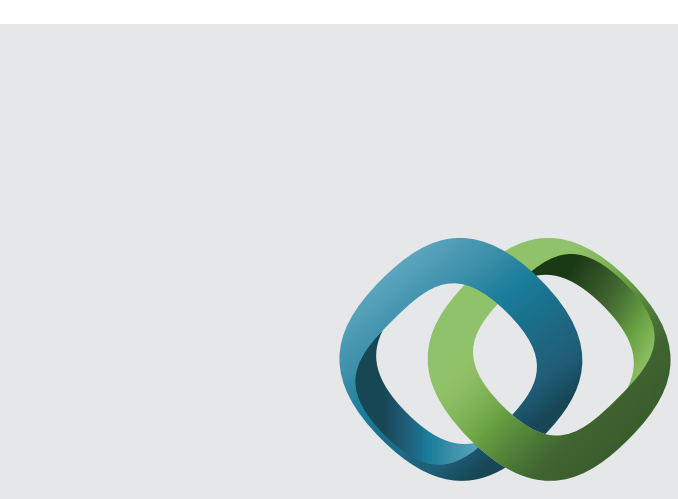

\section{Hindawi}

Submit your manuscripts at

http://www.hindawi.com
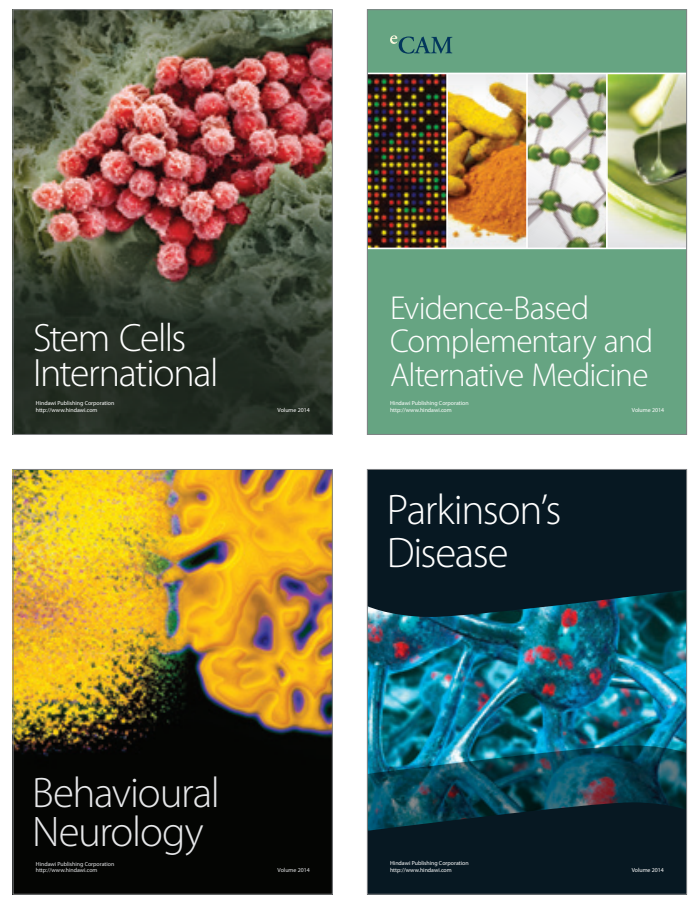
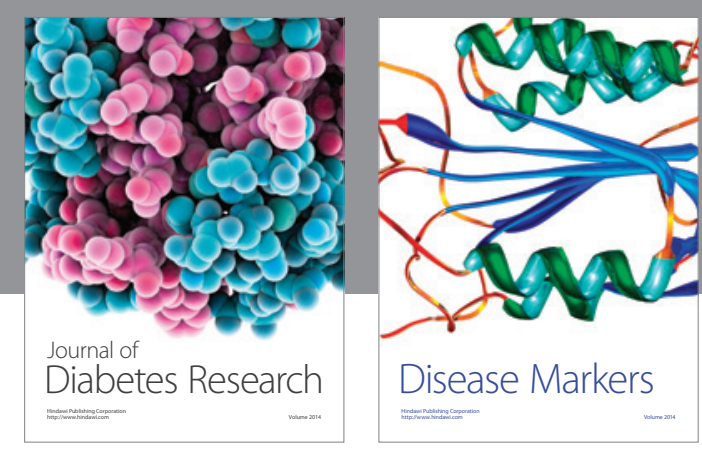

Disease Markers
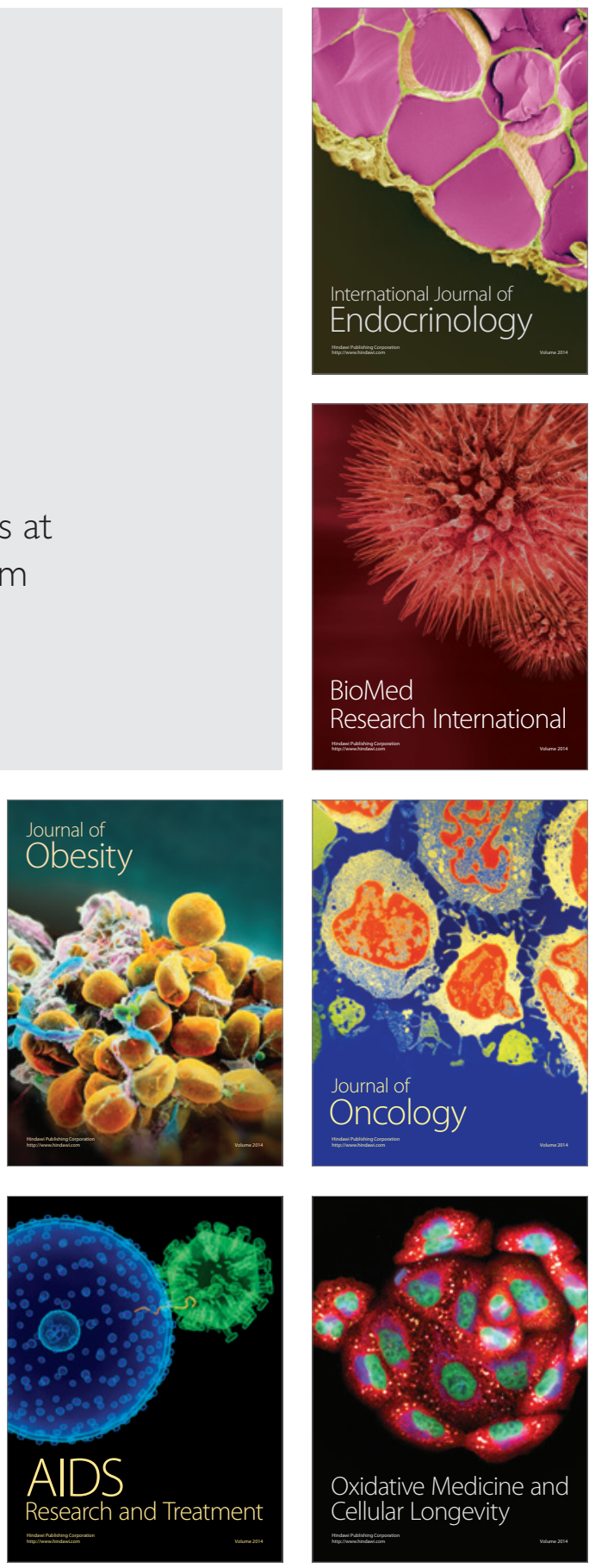